\title{
Artefatos digitais para o Museu DICA: contribuições para a formação de professores de Física
}

\author{
Matheus Barros ${ }^{1}$ \\ Mestrando em Ensino de Ciências e Matemática \\ Universidade Federal de Uberlândia \\ Silvia Martins ${ }^{1}$ \\ Museu Diversão com Ciência e Arte \\ Instituto de Física - Universidade Federal de Uberlândia \\ Uberlândia - MG
}

\section{Resumo}

No contexto das licenciaturas, pouco se ouve falar sobre espaços diferentes da escola para a realização de atividades didáticas. No entanto, pesquisas sobre práticas em espaços não formais, em especial os museus de ciência, vem aumentando cada vez mais. Nesse sentido, é importante que, além do incentivo às práticas em espaços fora da escola, também haja um despertar de interesse e treinamento para a efetivação de tais atividades. Desse modo, este trabalho apresenta uma pesquisa realizada com estudantes da disciplina de PROJETOS INTEGRADOS DE PRÁTICAS EDUCATIVAS 3 (PIPE 3), do curso de Física Licenciatura, da Universidade Federal de Uberlândia (UFU), no primeiro semestre de 2016, a fim de evidenciar as possiveis contribuições para a formação de professores de Física diante da construção de artefatos digitais para a exposição de Eletromagnetismo do Museu Diversão com Ciência e Arte - DICA. Nessa pesquisa, ficaram evidentes a evolução das concepções dos estudantes de PIPE 3 quanto aos museus de ciências, e o reconhecimento destes como espaços educativos e diferentes da escola; bem como os saberes despertados e agregados durante essa etapa da formação profissional. Desse modo, acreditamos que esse trabalho evidenciou as

\footnotetext{
${ }^{+}$Digital artifacts for the DICA Museum: contributions to the training of Physics teachers

* Recebido: novembro de 2019. Aceito: fevereiro de 2020.

${ }^{1}$ E-mails: matheus-barros@outlook.com; smartins@ufu.br
} 
vantagens em se trabalhar em espaços diferentes da escola na formação inicial de professores.

Palavras-chave: Museus de Ciências; Formação Inicial de Professores; Educação em Museus; Ensino de Física.

\begin{abstract}
In the context of undergraduate studies, there are not many experiences in discussing didactic activities considering places different from school. However, research on practices in non-formal spaces, especially the museums of science, have been increasing. In this sense, we believe to be important in teacher training programs and undergraduate studies to enhance the interest and training skills in out-of-school spaces for didactic activities. Thus, this paper presents our study with undergraduate Physics students, in a teacher training course named INTEGRATED EDUCATIONAL PRACTICES PROJECT 3 (PIPE 3) at the Federal University of Uberlândia (UFU), in the first semester of 2016. We intend to bring to light some possible contributions for Physics teacher training while they work in a proposal of digital artifacts for the exhibition of Electromagnetism from the DICA Museum. In this research, we found the evolution of the student's conceptions about science museums, and their recognition as educational spaces with objectives different from school. Therefore, we believe that this paper could evidence that the inclusion of educational activities involving nonformal spaces may contribute to teacher training in undergraduate studies.
\end{abstract}

Keywords: Science Museums; Initial Teacher Training; Museum Education; Physics Teaching.

\title{
I. Introdução
}

Os museus de ciências são um local de aprendizagem, com possibilidades para apresentação de uma ciência moderna, motivadora, desafiante e contextualizadora em relação ao ambiente pessoal, sociocultural e físico em que os visitantes estão inseridos (COLOMBO JR, 2014). Nesse sentido, o papel educativo dos museus de ciências, torna-se relevante e, assim, como ambiente educacional, esses espaços buscam contribuir para a popularização da ciência e a alfabetização científica da população, por meio de suas exposições, que podem ser consideradas a intervenção didática do museu (MARANDINO, 2016), e ações educativas. Além disso, uma vez que o público escolar representa parte significativa dos seus visitantes (JA- 
COBUCCI, 2008), também buscam contribuir para a melhoria do ensino de ciências nas escolas de educação básica, estabelecendo a necessidade de se pensar uma parceria entre o museu e a escola (MARANDINO, 2008).

Assim, entendemos que as reflexões acerca das parcerias entre o museu e a escola estão bastante associadas à forma com que os professores se relacionam com esses espaços. Nesse sentido, destacamos que os saberes dos professores trazem uma profunda marca social, como reflexos de suas experiências durante a formação inicial (ou continuada), bem como em experiências pessoais (TARDIF, 2002). Assim, esses saberes e experiências são incorporados à sua prática profissional e, de acordo com Carvalho (2009) e Silva (2012), adaptados e transformados a partir das vivências do docente ao longo de sua atuação. Nesse sentido, a atuação dos professores traz reflexos de sua formação inicial e é fortemente influenciada pela estrutura dos seus cursos de graduação.

Nesse cenário, de busca por estratégias de aproximação entre o museu e a escola, concordamos com as ideias de Ovigli (2009), de que as reflexões sobre o papel educativo dos museus na formação inicial podem contribuir para a valorização das visitas e atividades dos museus por parte dos professores da educação básica, além de colaborar para a formação de licenciandos para o trabalho como educadores de museus. Consideramos, portanto, que para permitir uma apropriação adequada dos espaços e exposições dos museus como parceiros da escola, seja relevante a abordagem de temáticas de educação em museus na formação inicial de professores, nos cursos de licenciatura nas áreas de ciências (Física, Química e Biologia).

Em muitos cursos de licenciatura, contudo, há uma maior valorização das disciplinas de conhecimentos específicos, em relação às de conhecimentos pedagógicos e/ou metodológicos (SANTOS, 2004; OVIGLI; BERTUCCI, 2009-b). Assim, as vivências que os estudantes de licenciatura têm em sua formação inicial, estão fortemente relacionadas com a reprodução dos modelos de seus professores e muitas vezes não valorizam diferentes práticas pedagógicas. Tais experiências têm grande influência nas práticas desses professores (TARDIF, 2002) pois, como cita Araújo e Vianna (2008), há uma dificuldade por parte dos licenciandos nas disciplinas de práticas de ensino em trabalhar temas além de uma perspectiva tradicional e pragmática.

Consideramos, portanto, que a formação do professor de ciências vai além dos conteúdos, de tal modo que formar um professor é também formar um educador, capaz de perceber as oportunidades de utilizar e realizar projetos sob diferentes enfoques e buscar situações inovadoras, como destaca Robilotta e Babichak (1997), para o ensino de Física:

Ensinar fisica é dificil. O ensino dessa matéria possui características muito peculiares, que abrangem diferentes áreas: a própria fisica, que engloba um amplo conhecimento e envolve ideias cada vez mais abstratas sobre uma parte do mundo natural, a educação, a matemática, a psicologia, a lingüística, a politica... (ROBILO TTA; BABICHAK, 1997, p. 35). 
No entanto, em relação aos museus de ciências, como espaços educativos e possíveis parceiros das escolas, percebemos que não há uma preocupação, por parte dos cursos de licenciatura em promover discussões e reflexões acerca das possíveis apropriações com os futuros professores (OVIGLI, 2009; SILVA, 2012). É importante, portanto, olhar para a formação inicial, considerando que os futuros educadores terão o papel de comunicar e divulgar ciência, assim, necessário se faz a presença de estágios e estudos em ambientes além do formal, particularmente em um museu de ciências, contribuindo dessa forma para o desenvolvimento de suas habilidades comunicativas (OVIGLI, 2009).

Existem, assim, poucas experiências que consideram os museus de ciências na formação inicial e, desse modo, mesmo quando existe um centro ou museu de ciências à disposição, não é claro para a maioria dos professores, mesmo da Universidade, as possibilidades que podem existir ao se apropriar desses espaços (OVIGLI, 2009; BARROS; MARTINS, 2015).

Nesse sentido, destacamos o trabalho de Oliveira (2011) que traz alguns apontamentos sobre a formação inicial, apresentando contextos em que se apropriar do museu para realizar uma atividade investigativa sobre Evolução, com licenciandos em Biologia, pode ser algo enriquecedor para o contexto da educação tanto formal, como não formal. Outro olhar sobre a formação inicial pode ser a participação de licenciandos como monitores de museus, considerando as possibilidades de melhoria das habilidades de comunicação do futuro educador e de uma maior compreensão e usufruto dos conceitos e definições aprendidos durante a graduação (CARVALHO, 2009; SILVA, 2012).

Nesse contexto, este trabalho se apresenta como uma proposta de abordagem das estratégias de criação de uma exposição virtual para um museu de ciências por uma turma de estudantes do segundo ano do curso de Licenciatura em Física, na disciplina obrigatória de PROJETO INTEGRADO DE PRÁTICAS EDUCATIVAS 3 (PIPE 3), que aborda o uso de Tecnologias Digitais da Informação e Comunicação (TDIC) para o ensino de Física, da Universidade Federal de Uberlândia (UFU). Desse modo, buscaremos compreender as relações dos futuros professores com o museu (seu papel educativo, suas missões e visões e suas linguagens), estabelecidas nesse processo de transposição (didática e museográfica) e quais as contribuições podem ser alcançadas durante a formação de professores de Física.

Essa proposta é feita aos estudantes como parte de uma exposição a ser implementada no Museu Diversão com Ciência e Arte - DICA, do Instituto de Física (INFIS), da UFU. E contou com o apoio do Núcleo de Pesquisas em Tecnologias Cognitivas (NUTEC), para a orientação e desenvolvimento dos recursos tecnológicos.

Assim, o objetivo deste trabalho é compreender as relações que os estudantes estabeleceram com os museus de ciências e o seu papel educativo, no processo de construção de artefatos digitais para integrar-se à exposição de "Eletromagnetismo: História e Cotidiano".

Além disso, considerando o contexto da disciplina, foi possível observar também as relações dos estudantes com os recursos tecnológicos como suporte para o ensino de conteú- 
dos de Física e com o conteúdo específico de Eletromagnetismo, pois estes três temas (museus, tecnologias e Eletromagnetismo) estiveram entrelaçados durante o processo.

Nesse sentido, buscamos apoio nas ideias de Tardif (2002) para dar suporte às reflexões deste trabalho. $\mathrm{O}$ alicerce foi formado pela definição de saber:

\begin{abstract}
[...] os pensamentos, as ideias, os juizos, os discursos, os argumentos que obedeçam a certas exigências de racionalidade. Eu falo ou ajo racionalmente quando sou capaz de justificar, por meio de razões, de declarações, de procedimentos, etc., o meu discurso ou a minha ação diante de um outro ator que me questiona sobre a pertinência, o valor deles. Essa capacidade [...] é verificada na argumentação, isto é, discurso em que proponho razões para justificar meus atos (TARDIF, 2002, p. 199).
\end{abstract}

Tal definição se faz muito importante para a construção da identidade do futuro professor de Física, visto que o saber protagonista aqui é o da formação profissional. Logo, será valorizado o que foi despertado e agregado conforme as vivências já acontecidas anteriormente à graduação, bem como as vivências apresentadas no contexto deste trabalho.

\title{
II. O museu DICA como pano de fundo para as ações do pipe 3 de 2016
}

O Museu DICA é um órgão complementar do INFIS da UFU e sua equipe de trabalho é composta por professores e funcionários do INFIS. Os alunos dos cursos de Física, assim como os da Química e das Ciências Biológicas, atuam como monitores nas exposições e atividades do museu.

Além disso, destacamos que muitos dos egressos do curso de Licenciatura em Física atuam como professores nas redes públicas e privadas da Uberlândia e região. Nesse sentido, de acordo com Barros e Martins (2015), de maneira geral os professores da educação básica da cidade têm pouca familiaridade com as possibilidades de colaboração entre o museu de ciências e os professores. Como parte da equipe educativa do museu, observamos que esse fato se repete mesmo para professores formados pelo curso de licenciatura do INFIS da UFU.

Essa relação evidencia que, mesmo o INFIS sendo responsável pela gestão e manutenção de um museu de ciências, esse fato pouco contribui para que seus estudantes conheçam o potencial educativo desse espaço. Assim, o professor do PIPE 3 aceitou o desafio de trazer a temática de museu, discutindo seu papel educativo, enquanto aborda o uso de tecnologias no ensino de Física. Ressaltamos que o objetivo da disciplina é o uso de tecnologias no ensino, conforme o Projeto Pedagógico do curso: "apresentar uma nova metodologia embasada nas novas Tecnologias da Informação e Comunicação (TIC), além do desenvolvimento de novas metodologias de ensino e materiais didáticos utilizando os recursos dessas novas TIC " (UFU, 2007), e o museu foi apenas o pano de fundo para as atividades desenvolvidas na disciplina.

A disciplina PIPE 3 de 2016 contou, inicialmente com 30 estudantes matriculados, porém, já na primeira semana esse número foi reduzido a 27 , e este se manteve até o fim do 
semestre. A maior parte dos estudantes estava no terceiro período do curso, cerca de $60 \%$, os outros $40 \%$ faziam parte de diferentes períodos desde o primeiro até o nono.

O projeto de construção de artefatos para o museu apresentou-se, portanto, como pano de fundo para a discussão do uso de tecnologias para o ensino de Física. Nesse sentido, os artefatos criados durante a disciplina tinham como objetivo integrarem-se à exposição "Eletromagnetismo: História e Cotidiano", do Museu DICA.

A exposição de "Eletromagnetismo: História e Cotidiano" do Museu DICA buscou fazer uma abordagem histórica e conceitual com o intuito de destacar a importância desse tema no dia-a-dia das pessoas. Não discorreremos mais sobre a exposição, pois esta não é o foco deste trabalho, visto que aspectos e caraterísticas relevantes sobre a exposição serão revelados à medida que forem necessários para as discussões. Além disso, não nos preocupamos em apontar os métodos e técnicas didáticas para a avaliação utilizada pelo professor da disciplina para a atribuição de notas e conceitos, nesse sentido, apontaremos apenas o enfoque utilizado para fomentar as discussões referentes à construção dos artefatos e à educação em museus.

Buscaremos compreender o impacto de uma ação que aproxime os estudantes do curso de licenciatura do Museu DICA e de outros museus de ciências, apesar do foco da disciplina, na qual foi desenvolvida os trabalhos, seja as tecnologias digitais. As discussões presentes nesse trabalho não estão relacionadas essencialmente ao uso de tecnologias, mas tem como ideia central as apropriações dos estudantes no contexto de museus de ciências e educação em museus. No entanto, apesar de não ser o foco do trabalho, foi possível observar também as relações dos estudantes sobre o uso de tecnologias como ferramenta para o ensino de Física, bem como com o conteúdo específico de Eletromagnetismo, pois estes três temas estiveram entrelaçados durante o processo.

Assim, buscamos compreender as relações que os estudantes estabeleceram com os museus de ciências (e seu papel educativo), no processo de construção de artefatos digitais (destacando o uso de tecnologias no ensino de conteúdos de Física) para integrar-se à exposição de "Eletromagnetismo: História e Cotidiano" (Reforçando a importância dos conhecimentos específicos para a qualidade da transposição, seja didática, seja museográfica).

\section{A proposta da disciplina: encaminhamentos do professor}

O professor da disciplina PIPE 3, utilizou a exposição "Eletromagnetismo: História e Cotidiano" como cenário para o desenvolvimento de propostas digitais como material instrucional.

Em parceria com a equipe do Museu DICA, o professor buscou (dentro das perspectivas da disciplina, de uso de artefatos digitais no ensino de Física) colaborar para a formação inicial de professores de Física, com o intuito de ampliar a compreensão dos objetivos de espaços como os museus de ciências e colaborar para que possam ser compreendidos como ambientes de educação científica e tecnológica. 
Como a temática de museus e seu papel educativo não eram de domínio dos estudantes, a primeira ação foi a apresentação de alguns referenciais teóricos sobre museus de ciências. Desse modo, o professor pôde discutir com os estudantes os objetivos dos museus como espaço educativo, as características do público que visita o museu, além dos elementos componentes da estrutura organizacional de uma exposição e do processo de transposição do saber científico para o ambiente do museu (MCMANUS, 1993; JACOBUCCI, 2008; MARANDINO, 2008).

Em seguida, com o apoio da equipe do Museu DICA, foi apresentada aos estudantes a exposição "Eletromagnetismo: História e Cotidiano", bem como a estrutura e objetivo do próprio museu. O professor, então propôs a atividade como uma possibilidade de colaboração para a ampliação da exposição, por meio de integração de artefatos digitais que promovessem uma melhor interação entre os visitantes e os conceitos científicos presentes na exposição. Desse modo, os estudantes de PIPE 3 se configuraram enquanto colaboradores do museu para a construção dos artefatos, com o intuito de que isso aumentasse o engajamento e a motivação na construção de seus saberes profissionais e contribuísse para que eles se sentissem protagonistas desse processo (TARDIF, 2002).

Para facilitar a ambientação dos estudantes à proposta e, como uma maneira de evidenciar que a proposta educativa ao museu é diferente da escola, o professor da disciplina criou e apresentou um personagem: o Sr. João Pipoqueiro. Esse personagem representa um visitante do museu e é uma pessoa muito curiosa e participativa diante dos conteúdos, discussões e interatividade que o museu tem a oferecer. Assim, todas as questões museográficas que envolviam o artefato a ser desenvolvido deveriam levar em consideração esse sujeito, principalmente a transposição dos conteúdos científicos.

Então, com essa proposta, o professor procurou desenvolver habilidades nos estudantes, tanto em relação ao uso de tecnologias digitais (que é o contexto dessa disciplina), de educação em museus e, ainda, discutir os conteúdos de Eletromagnetismo.

Os estudantes foram separados em equipes temáticas de acordo com os setores temáticos da exposição. Desse modo, eles compunham as equipes de Eletrostática, Geração de Energia Elétrica e Interações Eletromagnéticas. Cada equipe foi dividida em dois subgrupos, sendo:

i) Equipe de Roteiro: responsáveis por pensar de que forma seria o enredo da problemática que envolveria o artefato, para que cativasse o visitante durante a interação com o mesmo, além de ser composto por três estudantes e;

ii) Equipe de Recursos Tecnológicos: responsáveis por conciliar a TDIC escolhida com o enredo criado pela Equipe de Roteiro, composto por duas equipes, cada um com três estudantes.

A criação desses dois subgrupos se fez necessária para facilitar a orientação dos estudantes no desenvolvimento do projeto. Porém, mesmo que divididos em subequipes, todos eles tinham uma função em comum, que era de unir a TDIC com a história, de modo que os 
conceitos de Eletromagnetismo estivessem presentes e contextualizassem o visitante que interagisse com os artefatos a serem desenvolvidos. Para guiar as equipes com relação aos seus temas, um texto norteador com relação ao conteúdo de Física foi criado, de modo que ficasse claro o que cada temática englobava no contexto do Eletromagnetismo.

Segundo Mintz (2005) e Colombo Jr (2014) os conteúdos apresentados nas exposições de museus de ciências devem se dispor de forma a cativar o público quanto às discussões que são oferecidas, de modo que o museu seja tanto um espaço de lazer quanto de despertar interesse pelo aprendizado de temas científicos, ainda que em um nível bastante simplificado. Nesse sentido, o professor da disciplina entendeu que essa seria a melhor maneira de dividilos dentro das abordagens de museografia e transposição museográfica, além de não desconsiderar o caráter obrigatório da disciplina em se trabalhar com TDIC. Dessa forma, todas as equipes tinham como objetivo alcançar, dentro de seu contexto, a transposição do conteúdo de Física para essa exposição, de modo que entendam que o conteúdo é o real patrimônio em um museu de ciências e não os objetos.

Cada equipe temática (composta por nove alunos, cada uma) tinham duas equipes de recursos tecnológicos e uma equipe de roteiro, e assim cada um desses subgrupos de cada equipe temática deveria conter no máximo três estudantes. Ressaltando que a decisão de trabalhar com duas equipes de recursos tecnológicos foi dos estudantes, pois entenderam que assim conseguiriam dividir melhor os trabalhos.

Assim, durante a disciplina os progressos na proposta e construção dos artefatos, por parte dos estudantes, foram apresentados ao professor (e observados pelos pesquisadores) e as relações dos estudantes com os aspectos educativos do museu foram discutidos em 3 momentos diferentes:

Etapa 1: Esboços e ideias iniciais para os projetos;

Etapa 2: Avaliação e Reestruturação dos trabalhos por parte dos estudantes e;

Etapa 3: Reestruturações e Preparação para a Apresentação final dos trabalhos.

Além disso, entre as Etapas 1 e 2, nove dos 27 estudantes da disciplina fizeram uma viagem ao Rio de Janeiro, onde tiveram a oportunidade de conhecer dois museus de ciências (Museu da Vida e Museu do Amanhã), dividindo essa experiência com o restante da turma, o que contribuiu para as discussões sobre os projetos e colaborou para as reflexões dos alunos sobre seus trabalhos e suas relação com o museu como espaço de educação. Neste contexto, o professor da disciplina aproveitou a experiência dos alunos de modo que essa ação colaborou para o amadurecimento dos estudantes em relação à temática de educação em museus e permitiu ao professor discutir as abordagens presentes nesses espaços. Durante as visitas, o professor da disciplina orientou os estudantes que viajaram para, além da observação desses espaços, que interagissem com o público, com o intuito de colaborar para ampliar olhares dos estudantes do PIPE 3 com relação às propostas e missões dos museus, para além do espaço do Museu DICA, pois entendeu que estando os alunos comprometidos com o DICA era importante que também estivessem abertos para o olhar do visitante. 
As observações realizadas em cada uma das três etapas, assim como a visita aos museus do Rio de Janeiro, foram importantes para as reflexões sobre a evolução dos trabalhos e da construção de conhecimentos por parte dos estudantes.

\section{III.1 Orientação dos Trabalhos dos Alunos}

Durante o processo de proposta, apresentações e avaliações, os estudantes contaram com o apoio e orientação do professor da disciplina, e de outros colaboradores nesse trabalho de orientação:

- Aluna de doutorado que desenvolveu um trabalho sobre educação em museus sob a orientação do professor da disciplina;

- Representante do setor educativo do Museu DICA, que era estudante do oitavo período do curso de licenciatura em Física, sob a orientação da Coordenadora do Museu (autores desse trabalho) e;

- Licenciado em Física, que desenvolveu junto ao grupo NUTEC, trabalho de pesquisa e extensão na área de tecnologias digitais para o ensino de Física, também sob a orientação do professor da disciplina.

Nesse contexto, essa disciplina apresentou-se, por um lado, como um laboratório de pesquisa e extensão, por outro lado, buscou proporcionar aos estudantes um ambiente de trocas, ampliando as relações professor e alunos, estimulando interações com outros pesquisadores. Desse modo, entendemos que essa proposta fortalece a nossa ideia de que, enquanto museu universitário, o Museu DICA "não pode descartar, por um lado, a indissolubilidade entre ensino, pesquisa e extensão e, por outro lado, as características inerentes aos processos museais" (BRUNO, 2009).

Acreditamos que os impactos da proposta apresentada nesta disciplina são importantes para a reflexão acerca da abordagem de temas relacionados à educação em museus na formação inicial de professores. Além disso, entendemos que o envolvimento de outros pesquisadores no processo pode permitir aos estudantes ter uma visão ampliada do Instituto de Física e do curso de Licenciatura, por meio das trocas realizadas com a esquipe e o espaço do Museu DICA e com os pesquisadores da área de ensino.

\section{Organização da pesquisa}

Este trabalho se apresenta como uma pesquisa qualitativa, onde os métodos para a construção dos dados se baseiam na obra de Lüdke e André (1986). Essa pesquisa se configura como um estudo de caso (YIN, 2004), o qual se compreende que deve buscar novas respostas e indagações durante o desenvolvimento do trabalho, a partir do entendimento do contexto no qual a pesquisa está sendo realizada. 
Desse modo, foram identificadas e agrupadas categorias que revelam a visão dos estudantes de PIPE 3, referente ao papel do professor enquanto educador para todos os públicos (seja escolar ou qualquer outro público que frequenta o museu de ciências).

Nesse contexto, foram considerados dois aspectos norteadores para a análise dos dados: i) características evidenciadas quanto às concepções dos estudantes referentes aos museus de ciências, e; ii) saberes despertados e agregados para a docência. Segundo esses aspectos norteadores, emergiram-se três unidades de análise:

- reconhecimento do museu enquanto espaço educativo;

- entendimento sobre a museografia de uma exposição;

- condições de desenvolvimento do projeto em uma linguagem apropriada para o público leigo e boa qualidade da transposição museográfica realizada para o conteúdo de Física.

Além disso, buscamos destacar a relação dos estudantes em relação ao uso de tecnologias, de modo a não desconsiderar o caráter obrigatório da disciplina em se trabalhar com TDIC.

Diante disso, as etapas revelaram aspectos característicos de cada equipe, para cada uma das três unidades apontadas acima, e assim, foi possível identificar qual a concepção dos estudantes sobre os museus de ciências, quais saberes foram despertados e agregados e a que tipo de conhecimento esses saberes estão conectados, onde puderam ser classificados da seguinte maneira: $(\mathrm{N})$ - não entenderam; $(\mathrm{S})$ - entenderam; $(\mathrm{T})$ - evidências superficiais para se tirar alguma conclusão. Vale ressaltar que: apesar das categorias se apresentarem de forma positiva em uma determinada etapa, não garante que na etapa seguinte isso se mantenha ou melhore, visto que cada etapa traz experiências únicas que marcam a formação das ideias dos estudantes, reforçando nossa ideia de que a construção do conhecimento e os impactos das ações vivenciadas na graduação interferem nos saberes dos futuros docentes e, como destacado por Tardif (2002), acontece de forma complexa e não linear.

Os instrumentos para a construção dos dados foram vídeos, que foram gravados durante as aulas ao longo do semestre (de onde derivam todas as transcrições de falas), caderno campo (onde foram anotadas observações de acordo com a vivência de um dos autores do trabalho com estudantes e com os demais colaboradores da pesquisa).

No processo de leitura e interpretação dos dados, as etapas de apresentação dos projetos por parte dos alunos destacaram-se como momentos marcantes para a compreensão do processo de construção dos conhecimentos e nos permitiu refletir questões importantes para a consolidação de saberes para esses alunos que, esperamos, deverão deixar marcas em sua futura atuação como professor (TARDIF, 2002).

\section{O trabalho dos estudantes parte 1: esboços e ideias iniciais}

Durante a proposta inicial os estudantes apresentaram suas ideias e de que forma seu projeto estaria disposto no Museu DICA para que o visitante pudesse acessar. Apesar de uma 
visão geral positiva em relação a esta etapa, cada equipe apresentou características bem próprias, diante de suas falas, quanto ao uso da tecnologia digital escolhida, quanto aos conceitos do conteúdo de Eletromagnetismo e em relação ao enredo que envolveria o artefato.

Nessa primeira apresentação, observamos que os estudantes, das três equipes, não estavam preocupados com a forma como os conceitos físicos seriam abordados na atividade proposta. A preocupação dos grupos focou-se principalmente na escolha da TDIC, e na construção de um roteiro que envolveria o artefato. Essas observações, além de registradas no caderno de campo (nos momentos em que os alunos procuraram por orientação dos colaboradores da pesquisa, durante o período de planejamento), foram expressas nos vídeos gravados durante a aula correspondente à primeira apresentação das propostas de cada grupo temático.

Esse resultado foi, de alguma forma, esperado, considerando que as equipes de trabalho de cada grupo organizaram suas ações em 'roteiro' e 'tecnologia'. No entanto, os estudantes demonstraram compreender que os conceitos físicos deveriam estar presentes em suas proposições e demandariam aprofundamentos para o desenvolvimento dos trabalhos. Notamos, assim, que há uma desconstrução do pensar de que apenas os saberes específicos são importantes para formação profissional (TARDIF, 2002; SANTOS, 2004; OVIGLI; BERTUCCI, 2009-b) julgando que mesmo o conteúdo de Física sendo importante, há outros aspectos que devem ser considerados para a transposição desses conteúdos para o contexto museográfico (MARANDINO, 2016).

Ressaltamos que as observações sobre o que os componentes das equipes consideraram prioridade e desenvolveram primeiro, no trabalho, está relacionada com o perfil de cada equipe, de modo que cada grupo seguiu estratégias diferentes e escolheram trabalhar dessa maneira. Nesse sentido, os aspectos museográficos das propostas evidenciam as relações desses estudantes acerca de suas concepções sobre os museus de ciências, seu papel educativo e os elementos que devem fazer parte da exposição como recurso didático do museu (ACHIAM, 2014; MARANDINO 2016).

\section{V.1 Grupo 1: Noiva em Choque}

Assim, o Grupo 1, apresentou uma proposta de dramatização para a discussão dos assuntos de eletrostática:

[...] uma noiva em um carpete, andou pra lá e pra cá, essa coisa... Na hora de cortar o bolo, uma faca encrustada no bolo (uma faca sem capa) [...] e na hora dela pegar a faca encrustada no bolo, por estar eletrizada porque andou no carpete, andou pra lá e pra cá, ela tomou uma sútil descarga elétrica, e ela acha que saiu do bolo, só que bolo não dá choque, né [...] E vai ter todo um roteiro: Quem eletrizou a noiva? (ALUNO E1).

Essa proposta ressalta o desejo dos estudantes de aproximar a temática do cotidiano, trazendo aspectos de suas experiências com fenômenos de eletrização, presentes nos choques que são comuns na região da Uberlândia devido ao inverno seco. Esse elemento ressalta que 
esses estudantes compreendem o papel educativo do museu e a importância de discutir com o público os fenômenos do seu cotidiano, evidenciando o protagonismo de suas vivências sociais durante a construção do saber profissional enquanto educadores e professores de Física (TARDIF, 2002), seja para a escola ou para o museu de ciências. Do ponto de vista do museu, a proposta poderia ser explorada, mas, demandaria mais tempo que o disponível na disciplina e, de alguma forma, sugere um afastamento dos objetivos da disciplina de construção de artefatos digitais, dificultando sua implementação.

$\mathrm{Na}$ defesa do projeto pelo grupo, as tecnologias digitais estariam presentes nos mecanismos que fariam o artefato funcionar. No entanto, não ficou claro quem seriam os personagens (quem os representaria na realidade), pois segundo os estudantes, eles seriam pessoas reais (não deixando claro o papel das tecnologias).

Assim, apesar das dificuldades de organização da proposta e o afastamento dos objetivos da disciplina, é possível notar que há alguma tentativa de transposição museográfica dos conceitos e conteúdos físicos, quando os estudantes tentam contextualizar seus enredos fazendo uso de palavras como "choque", "descarga elétrica", "eletrizada", etc.

\section{V.2 Grupo 2: Jogo interativo}

O Segundo Grupo, que tinha como objetivo abordar o tema de geração de energia elétrica, bem como questões relacionadas à distribuição desta, propôs a construção de um jogo digital, que poderia ficar disponível ao público em um computador na exposição e no site do Museu DICA:

A gente pensou em criar um jogo pro museu, um jogo interativo [...] e o personagem, ele vai escolher alguns pontos no roteiro onde a história pode descambar pra um lado ou descambar pro outro [...] um ambiente que seria uma usina elétrica, essa usina por algum motivo para de funcionar [...] quatro personagens cada: um é especialista em um tipo de geração de energia elétrica (um de energia eólica, um de energia solar, e por aí vai...). E a gente desenvolveu o roteiro de forma que o João Pipoqueiro tivesse jogando lá na tela do computador e ele fiz... Guiasse esses personagens de acordo com a habilidade de cada um, num cenário onde ele conseguiria botar essa usina funcionando de novo, ou não. E aí, a gente faria com o que o Sr. João Pipoqueiro aprendesse um pouco dos processos de geração de energia elétrica e de transmissão de energia através do jogo, que a gente pensou que duraria entre cinco e dez minutos. (ALUNO G3)

É importante notar que essa equipe considerou aspectos importantes, como: tempo do visitante no artefato, conteúdo de Física relevante sobre o tema proposto e realidade do Museu DICA diante da equipe educativa disponível (ACHIAM, 2014; MARANDINO, 2016).

Consideramos que as experiências prévias dos estudantes tem papel importante na proposta das atividades, uma vez que o processo de transposição museográfica sempre carrega elementos da equipe que a propõe (MARANDINO, 2016). Assim, esse resultado sugere uma 
maturidade em relação à realidade dos museus de ciências que não encontramos no primeiro (ou no terceiro) grupo, evidenciando que os integrantes desse grupo possuem saberes específicos sobre museus, advindo de suas experiências pessoais, de atuação ou de formação (TARDIF, 2002).

Assim, consideramos relevante destacar o fato de que dos nove integrantes da equipe, três atuavam como monitores no Museu DICA, dois deles há quatro meses e o outro há cinco anos. Além disso, o monitor mais experiente possui uma maturidade acadêmica maior que todo o restante da equipe, pois, por estar no ambiente universitário há mais tempo atuou também na área de comunicação do Museu DICA, tendo colaborado com a comunicação de outras exposições, trazendo consigo saberes que valorizassem os objetivos do museu (TARDIF, 2002).

É importante ressaltar que as atribuições foram bem distribuídas dentro das equipes, de modo que cada um tinha um papel a ser cumprido e, consequentemente, não houvesse sobrecarga de um membro por acúmulos de tarefas desempenhadas. Desse modo, pôde-se evitar que os estudantes da Equipe 2 se aproveitassem do fato de ter membros da equipe do Museu DICA junto a eles; não garantimos que os membros do DICA não contribuíram de uma forma ou de outra no trabalho como um todo, mas acreditamos que isso colaborou para o desenvolvimento dos demais estudantes no protagonismo da construção de seus próprios saberes.

Em relação aos objetivos da disciplina, a proposta deixa claro o papel da tecnologia digital para a construção do artefato evidenciando, também nesse ponto, maturidade para a compreensão do ambiente em que essa proposta se insere.

\section{V.3 Grupo 3: Sala com desafios}

O Grupo 3, que ficou responsável pela abordagem da temática de interações eletromagnéticas, apresentou um artefato que dispunha de salas onde cada uma representava uma etapa com alguma problemática e a porta delas se abriria somente se a tal problemática fosse resolvida:

[...] a gente pensou em fazer um ambiente, todo climatizado, por exemplo: quando você entra num parque de diversões, e tem aqueles ambientes e passa pelo escuro, e você vai passando pelos corredores lá dentro [...] a gente fazer uma temática, por exemplo, tipo Indiana Jones, ele vai entrar tipo numa cuba [...] no caso do João Pipoqueiro, ele vai seguir, e aí vai ter uns puzzles pra ele resolver que caso vai ser os nossos experimentos. [...] A porta vai abrir e você vai passar pro próximo experimento só quando resolver esse, um exemplo seria... ah a gente faz toda um historinha, né, uma dramatizada lá, falar lá tipo: 'ah você tem que jogar luz branca nesse sensor aqui', e ai tem luz vermelha, luz branca, luz azul e ele vai perceber 'ah, mas não luz tem branca aqui', [...] ele vai começar a misturar as cores. (ALUNO I2) 
Percebemos que os integrantes dessa equipe não compreendiam muito bem a dinâmica dos museus de ciências, especialmente do Museu DICA, além da fala na apresentação da proposta, durante a procura por orientações os estudantes não se ativeram às informações adquiridas sobre o Museu DICA e o contexto da exposição. Apesar de apontarem fenômenos físicos, tais como: absorção de luz e mistura de frequências da luz visível, seu discurso não se apresentava de forma consistente com relação a eles. A maior preocupação era com o efeito de entretenimento que o artefato causaria nos visitantes (MINTIZ, 2005), perspectiva essa que pode ter origem de suas vivências anteriores com os museus (TARDIF, 2002), seja como visitante ou por influência de opiniões de pessoas próximas (familiares, amigos, professores, etc.).

É possível perceber, no entanto, que apesar dos recursos tecnológicos interessantes para o contexto do museu, o grupo não possuía clareza sobre a forma como essa ação seria implementada no museu. Além disso, destacamos que a atividade proposta só poderia ocorrer com a disponibilidade de um mediador em todo ao processo. As visitas escolares guiadas são práticas comuns nos museus de ciências e, uma vez que essa questão não foi apresentada pelo professor da disciplina ou demais pesquisadores na apresentação da proposta, acreditamos que essa demanda possa ser originária de uma experiência anterior (TARDIF, 2002).

\section{V.4 Um olhar sobre a primeira etapa}

As experiências apresentadas nessa seção tiveram, assim, o intuito de revelar aspectos característicos de cada equipe e identificar a concepção dos estudantes sobre os museus de ciências, quais saberes foram despertados e agregados e a que tipo de conhecimento esses saberes estão conectados. Assim, um panorama das observações que consideramos importantes para compreender a visão de cada grupo, acerca dos museus de ciências e o uso de tecnologias para a abordagem de conceitos físicos, é apresentado na Tabela 1.

Tabela 1 - Propostas iniciais dos estudantes e suas relações com o museu: (N) - não entenderam; (S) - entenderam; (T) evidências superficiais para se tirar alguma conclusão.

\begin{tabular}{|l|c|c|c|}
\hline & \multicolumn{1}{|c|}{ Grupo 1 } & \multicolumn{1}{c|}{ Grupo 2 } & \multicolumn{1}{c|}{ Grupo 3 } \\
\hline Proposta dos Estudantes & $\begin{array}{l}\text { Dramatização: Noiva em } \\
\text { choque. }\end{array}$ & $\begin{array}{l}\text { Jogo interativo: geração de } \\
\text { energia. }\end{array}$ & $\begin{array}{l}\text { Sala com desafios: } \\
\text { resolução de problemas } \\
\text { de Física. }\end{array}$ \\
\hline $\begin{array}{l}\text { Entendimento sobre a } \\
\text { museografia da exposição }\end{array}$ & $\mathrm{N}$ & $\mathrm{S}$ & $\mathrm{N}$ \\
\hline $\begin{array}{l}\text { Reconhecimento do Museu } \\
\text { como espaço educativo }\end{array}$ & $\mathrm{S}$ & $\mathrm{S}$ & $\mathrm{S}$ \\
\hline $\begin{array}{l}\text { Linguagem apropriada e } \\
\text { qualidade da transposição }\end{array}$ & $\mathrm{T}$ & $\mathrm{T}$ & $\mathrm{T}$ \\
\hline $\begin{array}{l}\text { Uso de tecnologias (ade- } \\
\text { quação aos objetivos da } \\
\text { disciplina) }\end{array}$ & $\mathrm{T}$ & $\mathrm{S}$ & $\mathrm{T}$ \\
\hline
\end{tabular}


Nesse sentido, de maneira geral, percebemos que, com exceção do grupo 2, essa fase inicial da proposta evidenciou que, apesar das discussões promovidas sobre museus de ciências e seu papel educativo (MCMANUS, 2013), os estudantes não possuem uma imagem clara sobre como a exposição pode funcionar como recurso didático do museu (MARANDINO, 2016), isso ficou evidente tanto nas falas durante as apresentações dos trabalhos, quanto na procura por orientação durante a elaboração das propostas.

Desse modo, os produtos apresentados pelos alunos, até aqui, evidenciam as marcas de seus saberes (TARDIF, 2002), adquiridos em suas vivências anteriores à disciplina, sejam eles advindos de suas experiências cotidianas ou acadêmicas, evidenciando os olhares que cada um deles tem sobre o museu.

Além disso, com o resultado apresentado pelo grupo 2, percebemos que o envolvimento de monitores de um museu de ciências em processos de curadoria do museu promove a apropriação de conceitos importantes sobre os objetivos do museu e os elementos que são relevantes para a proposta de exposições. Acreditamos, assim, que essas experiências contribuíram para a consolidação de saberes (TARDIF, 2002) que irão acompanhar esses estudantes em suas atuações profisssionais, reforçando a importância da atuação dos estudantes dos cursos de licenciatura nas equipes educativas do Museu.

As reflexões promovidas pelo professor durante a realização das apresentações, nessa etapa, encaminharam as ações a serem desenvolvidas nas etapas subsequentes.

\section{Viagem ao Rio de Janeiro: visita ao Museu da Vida e ao Museu do Amanhã}

Durante o período de realização da disciplina, após a apresentação da primeira proposta de exposição por parte dos alunos (Primeira Etapa), alguns estudantes tiveram a oportunidade de participar de uma viagem ao Rio de Janeiro, em que foram realizadas duas visitas, uma ao Museu da Vida e outra ao Museu do Amanhã.

Essa atividade realizada pelo Instituto de Física representou uma oportunidade para que esses estudantes pudessem vivenciar propostas museográficas diferentes, permitindo que o professor orientasse suas observações e promovesse discussões sobre os objetivos e perfis dos museus de ciências. Assim, nove estudantes participaram dessa viagem e com as orientações do professor e de outros colaboradores da disciplina, que os acompanhou nas visitas, apresentaram aos outros estudantes (que não tiveram a oportunidade de participar da viagem) suas observações.

O professor da disciplina entregou aos estudantes um documento com questões norteadoras para orientar as observações e estimular os estudantes a refletir sobre esses espaços, abordando diversos aspectos como: i) como eram os artefatos e como eles se organizavam e eram apresentados no museu; ii) Quais os conteúdos (relacionados às diferentes áreas do conhecimento) podiam ser percebidos nas exposições; iii) Quais os recursos tecnológicos digitais, caso existissem, estavam presentes nas exposições e como eles colaboravam para a exposição como um todo; iv) qual era o público que estava presente no museu no momento de 
suas visitas. Além disso, os alunos foram estimulados a conversar com outros visitantes para entender suas relações com os espaços e com as exposições. Com isso, o professor buscou estimular os estudantes a refletirem a importância e o desafio do trabalho de transposição museográfica (ACHIAM, 2014; MARANDINO, 2016)

Assim, de volta à Uberlândia, com os questionamentos disponibilizados pelo professor para as reflexões dos estudantes durante a visita, os nove estudantes apresentaram ao restante da turma suas impressões. Algumas falas, que apareceram nesse momento evidenciaram que esses estudantes estavam atentos aos diversos aspectos da exposição que pudessem promover o interesse do público (nesse momento, representado principalmente por eles mesmos) e que favorecem a abordagem dos conteúdos científicos. Nessas falas foram identificadas, de certa forma, uma mudança dos olhares sobre os museus de ciências, onde os estudantes evidenciaram as seguintes características quanto às suas concepções sobre museus de ciências:

[...] mostra para os visitantes, já no começo com uma introdução histórica porque os antigos já mostravam interesse em estudar o corpo tanto na parte física e psicológica. E... depois já entra pra aqueles experimentos lá [...]. (ALUNO E3)

Eram umas mesas, com... com informações touch screen todas elas, e eu percebi que a maioria do pessoal não gostou das mesas, porque não era algo interativo, [...] percebi que é interessante pro museu algo mais dinâmico e que prenda a atenção. (ALUNO E1)

Durante a conversa na sala de aula, ficou evidente que os estudantes entenderam sobre como é a disposição de experimentos em um museu de ciências (NASCIMENTO; VENTURA, 2001; MINTZ, 2005) e como funciona uma visita no espaço, percebendo diferença entre a visitação livre e a visitação guiada (MARANDINO, 2008), abrindo caminho para que pensassem sobre como seria o impacto do artefato, por eles construído, no espaço do Museu DICA, sendo que todos os estudantes de PIPE 3 conhecem o museu do INFIS e o público que o visita.

Nesse contexto, também se observou que estudantes fizeram uma análise sobre o conteúdo e a transposição disposta em cada experimento com que interagiram, identificando elementos que despertassem interesse e a buscar mais sobre a ciência em seu cotidiano, sendo o museu um lugar com uma proposta moderna, desafiante, motivadora e contextualizadora, como propõe Colombo Jr (2014). Além disso, após as reflexões realizadas, percebeu-se grande envolvimento de toda a turma e anseio em continuar com o trabalho, não somente aqueles que viajaram, mas também os que participaram da apresentação e das discussões. Entendemos, assim, que as discussões colaboraram para compreensão de aspectos importantes do processo de transposição e o papel dos artefatos construídos para a exposição favorecendo assim, a consolidação de saberes (TARDIF, 2002) que devem contribuir para o desenvolvimento dos trabalhos dos estudantes no seu processo de formação docente. 


\section{O trabalho dos estudantes parte 2: avaliação e reestruturação}

A segunda etapa de realização do trabalho por parte dos alunos foi marcada pelas apresentações dos projetos, depois que esses passaram por reflexões, novas pesquisas e se reestruturaram, para nova discussão com o professor e a turma.

Lembramos que, a viagem ao Rio de Janeiro e as discussões realizadas em sala de aula com os estudantes, no retorno à Uberlândia, aconteceram durante essa segunda etapa, de modo que tem influência no olhar dos alunos e na sua relação com os artefatos e o Museu DICA.

Durante o período de um mês, entre a primeira e a segunda etapa, os estudantes puderam buscar orientação tanto com o professor da disciplina como com a equipe de apoio para a elaboração e desenvolvimento das propostas.

\section{VII.1 Grupo 1: Quiz com conceitos de Eletromagnetismo}

Nesse momento, a apresentação do grupo 1 trouxe uma proposta diferente daquela da primeira etapa e, em lugar de tentar elaborar uma apresentação, a equipe apresentou a ideia de elaborar um Quiz, onde haveria uma situação (apresentada por um vídeo) para contextualizar os fenômenos envolvidos, seguido da pergunta e as alternativas, e por fim outro vídeo com a resposta, em que:

[...] encaixaria três experimentos do museu que seriam mencionados, pelo monitor da visita, convidando o visitante conhecê-los e experimentar as situações apresentadas e conhecer a exposição. (ALUNO E2)

Vale a ressalva de que esse grupo buscou apoio do NUTEC e do Museu DICA, a fim de conhecer mais sobre a exposição e chegar a alguma ideia de recurso tecnológico, diante das possibilidades reais do Museu DICA, dentro do contexto do conteúdo e do tipo de espaço educacional para quem estavam desenvolvendo a proposta educativa.

Nessa proposta os integrantes do grupo reforçaram a necessidade de um monitor para guiar as ações dos visitantes, levando-os a interagir com o artefato, sem que se preocupassem de deixar clara a conexão desse artefato com outros objetos do museu. Percebemos, assim, que o grupo ainda apresentava dificuldades para entender o papel da organização dos objetos no contexto da exposição e que o processo de transposição é mais do que a disponibilização de objetos e informações (ACHIAM, 2014).

Esse olhar da equipe para a necessidade de um monitor guiando as ações dos visitantes, de alguma forma, evidencia que esses estudantes ainda possuem uma visão escolarizada do museu, de modo que as atividades propostas possuem formatos de "mini-aulas" devendo sempre contar com a presença de um mediador (professor ou monitor). Assim, durante as discussões buscamos destacar elementos da organização dos objetos no ambiente do museu e 
lembrá-los de que muitos visitantes transitam pelas exposições sem, muitas vezes, desejar o acompanhamento dos monitores.

Apesar do olhar escolarizado do museu, entendemos que o Quiz apresentado por esse grupo, representa uma proposta promissora. Percebemos que os estudantes se preocuparam com a contextualização das questões que seriam apresentadas no Quiz, de modo a serem de interesse do visitante (MINTZ, 2005; COLOMBO JR, 2014) levando-o a reflexões sobre o cotidiano que vivenciam.

Em relação aos conteúdos selecionados para o jogo, foram apresentados sem erros conceituais com relação ao saber sábio do Eletromagnetismo (CHAVELLARD, 1991; MARANDINO, 2008; ACHIAM, 2014). No entanto, observamos que apresentava um formato muito próximo de um livro texto, como no exemplo a seguir:

Duas esferas idêticas, uma eletrizada negativamente e outra neutra são colocadas primeiramente em contato e logo depois afastadas. Sabendo-se, que não há troca de cargas elétricas com o meio exterior, qual será a carga que ambas irão adquirir após o contato? (QUIZ, ETAPA 2, GRUPO 1)

As partículas mais leves, ainda em forma de vapor de água, deslocadas para a parte mais alta da nuvem, estão carregadas positivamente, já as partículas de gelo, deslocadas para a parte mais baixa da nuvem, tem carga negativa. Neste caso, selecione a alternativa correta. (QUIZ, ETAPA 2, GRUPO 1)

Além disso, os recursos audiovisuais possíveis de serem utilizados no trabalho não foram explorados em toda sua potencialidade, repleto de textos longos que eram necessários serem lidos para que o visitante pudesse responder às perguntas. Nesse sentido, foi possível perceber um crescimento da equipe em relação à primeira etapa. No entanto, percebemos que as marcas das suas experiências enquanto estudantes (TARDIF, 2002), dificultam a compreensão dessa equipe em relação à linguagem e a pedagogia do museu (ACHIAM, 2014; MARANDINO, 2016).

Nesse sentido, as discussões com o professor e com a turma indicaram aos estudantes a leitura e reflexões de um texto que discute a pedagogia do museu de forma simples para ajudá-los a compreender a diferença entre o museu e a escola como espaços de educação (MARANDINO, 2008). Além disso, foi sugerido que os estudantes buscassem mais apoio com os colaboradores da equipe de orientação da disciplina que poderiam colaborar tanto nas suas reflexões sobre o processo de transposição quanto para o uso dos recursos tecnológicos.

\section{VII.2 Grupo 2: A primeira versão do jogo}

O grupo 2 foi a única equipe que manteve a sua proposta inicial, e já nesta etapa apresentou o que seria a primeira versão do jogo, com layout e trilha sonora. Assim, eles prepararam o projeto do artefato, os instrumentos e ferramentas utilizadas (tecnologias, imagens, 
trilha sonora) e estrutura, mas não apresentaram os conteúdos, que deveriam estar presentes na versão final, de forma clara.

As imagens de pessoas utilizadas pelos estudantes em seus trabalhos foram retiradas de fontes livres de direitos autorais, com isso podemos identificar um caráter ético por parte deles, onde se apropriaram de um saber pessoal (TARDIF, 2002), ou seja, um saber além dos relacionados aos conteúdos dos trabalhos desenvolvidos. Além disso, é interessante notar na capa do jogo como foi representado o Sr. João Pipoqueiro, que é o personagem criado pelo professor da disciplina para falar com os estudantes sobre a diversidade do público que visita o museu - não se restringindo ao publico escolar (MARANDINO, 2008).

Essa equipe, mais uma vez, demonstrou mais maturidade que as outras para a discussão, tanto da proposta, quanto dos recursos utilizados para sua construção, que acreditamos que seja uma consequência dos saberes que se relacionam com as experiências de parte dessa equipe como monitores do Museu DICA (TARDIF, 2002). Assim, em um momento de discussão após a apresentação sobre o jogo, os estudantes levantaram questões relevantes sobre qual tecnologia digital iriam utilizar e os elementos que os influenciaram na tomada de decisões:

A vantagem do flash é que daria pra jogar no site do DICA, por exemplo, deixar online pra baixar como aplicativo. (ALUNO G4)

$\dot{E}$, por enquanto, no começo pra deixar na exposição do DICA seria o powerpoint [...] o que é uma coisa interessante, muita gente não sabe que o powerpoint dá pra ser utilizado assim, fazer às vezes um jogo, e aí, é isso. Do conteúdo do roteiro, como a gente falou, escolhemos o que seria viável colocar dentro da realidade da comunidade do João Pipoqueiro, os tipos de geração de energia que seriam viáveis. (ALUNO G3)

Percebemos, portanto, que além dos aspectos relacionados à comunicação no museu (visto a beleza e disposição dos elementos do que foi apresentado), os estudantes também se preocuparam em estudar sobre tecnologias bem como os seus usos por parte de quem desenvolve um trabalho. Também consideraram o tempo que se tinha na disciplina para escolher em qual ferramenta desenvolver o jogo, no entanto não desconsideraram o fato de melhorar o artefato para que este fizesse parte dos acervos permanentes do museu.

No entanto, a equipe não deixou clara, durante a apresentação nesta etapa, como a transposição do conteúdo de Física estava contextualizada no jogo. As discussões feitas nesse momento sobre os conceitos e fenômenos que estariam presentes no jogo, reforçaram o conhecimento da equipe sobre os assuntos, mas não deixaram claro como esses conceitos estariam presentes no jogo. 


\section{VII.3 Grupo 3: Sala de Experimentos}

A Equipe 3 não apresentou nenhuma mudança significativa em relação à proposta inicial, pensando ainda na ideia de uma sala com artefatos (objetos reais, não virtuais), no entanto reduziram o tamanho dos experimentos:

A ideia é o feixe de laser seguir o caminho da água [...] então a gente tá só confirmando se é viável a construção de todos, a gente tá correndo atrás do material.[...] ele se relaciona com as sombras coloridas, aquele... esse mesmo. (ALUNO I2)

Nesse sentido, os estudantes ainda não tinham clareza de como integrar os objetivos da disciplina aos objetivos do museu. Assim, para eles, a ideia de uma proposta para o museu deveria partir da proposta de novos objetos reais e não conseguiam visualizar uma contribuição usando tecnologias digitais. Além disso, os experimentos apresentados pelos estudantes estão mais relacionados aos conteúdos de Óptica do que ao de Eletromagnetismo, evidenciando uma grande desatenção em relação às demandas do professor da disciplina ou uma confusão acerca do que significa a ideia de complementação da exposição.

Assim, o grupo propôs um conjunto de experimentos que deveriam ser apresentados aos visitantes no formato de uma visita palestra (MARANDINO, 2008). Poderíamos supor que essa proposta seja um indicativo da dificuldade desses estudantes em trabalhar com recursos digitais, no entanto, os estudantes destacaram que não teriam dificuldades com as ferramentas, mas evidenciou uma dificuldade criativa por parte da equipe.

Ao considerarmos que a exposição já possui os objetos para a interação direta com o público e que a proposta foi de complementação com artefatos digitais que colaborassem e complementassem a exposição, acreditamos que os estudantes tenham confundido os objetivos da proposta e acreditam que a única forma de abordar conceitos físicos é por meio de experimentos.

Considerando o contexto das experiências e de como são acumuladas de acordo com Tardif (2002), acreditamos que a ideia de que sua proposta deva necessariamente ser por meio de experimentos reais evidencia a ideia que esses estudantes carregam que a única forma de abordar conceitos físicos seja por meio de experimentos, o que pode estar relacionado com suas experiências para a abordagem de conteúdos de Física por meio de experimentos durante o curso de licenciatura em Física.

Entre as orientações do professor, foi sugerido que os estudantes procurassem novamente a equipe do Museu DICA, para conhecer melhor a exposição e os projetos que estavam desenvolvendo para a comunicação do museu.

\section{VII.4 Um olhar sobre a segunda etapa}

A Tabela 2 apresenta o panorama das relações dos grupos, nessa etapa, com os museus de ciências e o uso de tecnologias, evidenciando que a relação dos três grupos com rela- 
ção à proposta evoluiu de forma diferente e mostra indícios de que o processo de apropriação, por parte dos alunos (futuros professores de Física), do museu como espaço de educação não se dá de forma simples.

Acreditamos que a visita aos museus do Rio de Janeiro permitiu aos alunos construir suas próprias ideias em relação à abordagem dos conteúdos nesses espaços e essas percepções estavam presentes nas suas propostas.

Tabela 2 - Propostas iniciais dos estudantes e suas relações com o museu: (N) - não entenderam; (S) - entenderam; (T) evidências superficiais.

\begin{tabular}{|l|c|c|c|}
\hline & \multicolumn{1}{|c|}{ Grupo 1 } & \multicolumn{1}{c|}{ Grupo 2 } & \multicolumn{1}{c|}{ Grupo 3 } \\
\hline $\begin{array}{l}\text { Proposta dos Estudantes: } \\
\text { Evolução do trabalho em } \\
\text { relação à Etapa 1 }\end{array}$ & $\begin{array}{l}\text { Quiz com conceitos de } \\
\text { Eletromagnetismo }\end{array}$ & $\begin{array}{l}\text { Continuaram com a } \\
\text { proposta do Jogo intera- } \\
\text { tivo }\end{array}$ & $\begin{array}{l}\text { Experimentos a serem } \\
\text { apresentados pelos } \\
\text { monitores }\end{array}$ \\
\hline $\begin{array}{l}\text { Entendimento sobre a } \\
\text { museografia da exposição }\end{array}$ & $\mathrm{T}$ & $\mathrm{S}$ & $\mathrm{N}$ \\
\hline $\begin{array}{l}\text { Reconhecimento do Mu- } \\
\text { seu como espaço educati- } \\
\text { vo }\end{array}$ & $\mathrm{S}$ & $\mathrm{S}$ & $\mathrm{S}$ \\
\hline $\begin{array}{l}\text { Linguagem apropriada e } \\
\text { qualidade da transposi- } \\
\text { ção }\end{array}$ & $\mathrm{T}$ & $\mathrm{T}$ & $\mathrm{T}$ \\
\hline $\begin{array}{l}\text { Uso de tecnologias (ade- } \\
\text { quação aos objetivos da } \\
\text { disciplina) }\end{array}$ & $\mathrm{S}$ & $\mathrm{S}$ & $\mathrm{N}$ \\
\hline
\end{tabular}

O grupo 1, com a proposta do Quiz, evidenciou sua percepção sobre a importância das interfaces digitais para a interação do público, como vivenciado principalmente nas exposições visitadas por eles no Museu do Amanhã. No entanto, não conseguiram compreender como o museu dialoga com o público e, assim, os conteúdos estavam presentes em seu artefato segundo suas próprias relações com a Física, que se deram principalmente nos ambientes escolares e acadêmicos, como apontado por Tardif (2002). Assim, para o primeiro grupo, percebemos que os saberes oriundos de suas experiências vividas na disciplina entrelaçaram-se com suas visões sobre o ensino de Física, interferindo na forma como fizeram sua proposta.

O grupo 2 evidenciou, nessa etapa, seus conhecimentos sobre as tecnologias, trazidos de suas experiências anteriores (TARDIF, 2002) e de suas pesquisas para a construção do artefato. Ressaltamos que para esse grupo, o impacto das visitas aos museus do Rio não ficou evidente, uma vez que já na primeira etapa o grupo apresentou maturidade nas reflexões sobre os museus como espaços educativos e sobre o processo de transposição (MARANDINO, 2008; ACHIAM, 2014). 
O grupo 3 revelou confusões em relação à proposta do trabalho e, ao que parece, a visita aos museus no Rio de Janeiro, não contribuiu para que eles percebessem o papel da tecnologia no museu. Acreditamos que as dificuldades desse grupo revelam um pouco da complexidade do processo de aprendizado, em que o contato com novos conhecimentos demanda um tempo para o amadurecimento, que depende dos próprios indivíduos que as constroem dentro de si (TARDIF, 2002), visto que o tempo da disciplina é curto para a consolidação de algum saber experiencial sobre a educação em museus. Assim, apesar de não terem feito uma proposta coerente em relação às orientações do professor, é necessário aguardar até a próxima etapa para saber se essas confusões são parte do processo de aprendizado. Nesse momento, esperamos que as orientações dadas pelo professor (e as disponibilidades dos colaboradores) ajudem esses alunos a entender o contexto da proposta de um artefato para a exposição e os objetivos pedagógicos do museu (MARANDINO, 2008), visto que a construção do saber experiencial depende também das vivências com outros indivíduos do espaço em que trabalha (TARDIF, 2002).

\section{O trabalho dos estudantes parte 3: apresentação final}

A preparação para a proposta final dos trabalhos foi feita por três semanas, e demandou esforços diferentes de cada uma das equipes.

\section{VIII.1 Grupo 1: Quiz com conceitos de Eletromagnetismo no cotidiano}

Na apresentação do trabalho final, o grupo 1 apresentou um Quiz com cinco situações, onde, em cada uma delas, apresentava-se a estrutura da Fig. 1.

A etapa (B) que aparece na Fig. 1 mostra o recorte de uma cena do vídeo, e, igualmente na etapa (D), correspondem à situação física para a visualização por parte do visitante. Algo que chama a atenção nos vídeos é que os próprios estudantes se dispuseram a serem os atores, além disso, tiveram a autorização para utilizarem o espaço do Museu DICA na UFU para a realização das gravações. Porém, o caminho a ser trilhado da etapa (B) para a etapa (C), foi bastante dificultoso, pois o pessoal se deparou com inúmeros enganos procedimentais na realização dos experimentos.

Do ponto de vista de aprendizado, isso foi muito rico, pois a partir dos erros foram realizadas várias discussões em torno dos fenômenos e conceitos de Eletrostática, de modo a apontar quais eram as possíveis situações, ou não, fisicamente para que a prática tivesse sucesso; conforme registrado pelo autor desse trabalho no caderno de campo, enquanto acompanhou a equipe nas gravações para o Quiz. Isso se configura do despertar e agregar de um saber profissional do ponto de vista de Tardif (2002), e não significa que esses saberes se manterão para sempre da mesma forma nos integrantes dessa equipe, porém, é um bom ponto de partida para que possam ser aperfeiçoados durante os trajetos profissionais que essas pessoas seguirão, visto que, assim como o contexto das situações físicas, os públicos que trabalharão (seja 
na escola ou no museu) serão variados e terão suas particularidades, as quais necessitarão de adaptações para a consolidação de um saber-fazer (TARDIF, 2002).

Nesse contexto, uma segunda discussão surgiu, e foi nela que houve a conclusão da transposição museográfica, pois com a elaboração das situações problematizadoras e a unção com o conteúdo simplificado, eles notaram que alguns enunciados do Quiz não faziam sentido, se tomarem como base a discussão realizada para a gravação do vídeo e a correta utilização dos conceitos e fenômenos de Eletrostática, o que corrobora com as ideias de Ovigli (2009) e Silva (2012) quanto ao treinamento da transposição para um público diferente do escolar.

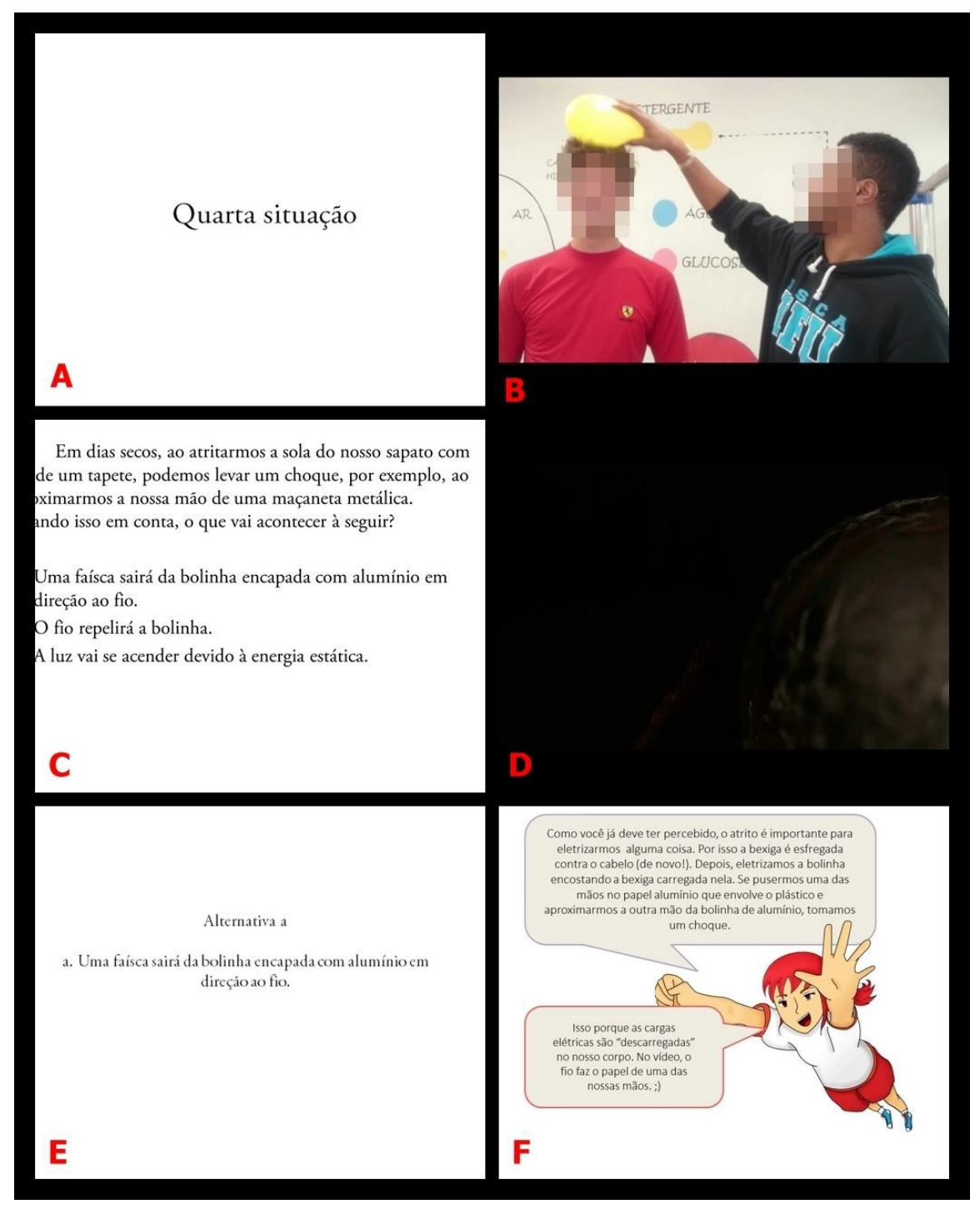

Fig. 1 - Referente a uma questão proposta pelo Quiz, onde: (A) informação da posição do visitante; (B) vídeo introdutório; (C) questão problematizadora e alternativas; (D) video de resposta; (E) mensagem de resposta; $(F)$ justificativa da alternativa correta. 
Desse modo, ficou evidente que apenas o vídeo da etapa (D) e o slide da etapa (E) não eram suficientes para esclarecer os acertos ou erros do visitante e, assim, foi criada a etapa (F), com a conclusão da contextualização e clareamento quanto à situação física abordada em cada questão. Pode-se notar, diante da Fig. 1, que a interface do Quiz ficou apresentável para ser utilizada em uma exposição museal segundo as ideias de Marandino (2001), Nascimento e Ventura (2001) e Mintz (2005) de modo que há grande potencial para cativar o visitante, isso se deve também à boa escolha do recurso tecnológico empregado e manipulado.

\section{VIII.2 Grupo 2: Jogo com Discussões sobre transformações de Energia}

O grupo 2, nessa última etapa, apresentou o jogo, ainda incompleto devido às dificuldades do recurso tecnológico utilizado e o tempo disponível para o desenvolvimento destes. O jogo se constituía de um cenário em que o Sr. João Pipoqueiro era o personagem principal e guiado pelo visitante que interagisse com o mesmo. Neste contexto, o pessoal da cidade de "Dicópolis" tentaria resolver o problema de fornecimento de energia elétrica por parte da usina hidrelétrica da cidade, a qual estava enfrentando problemas estruturais; com a ajuda do Sr. João Pipoqueiro, o problema seria resolvido de modo que ele visitaria uma companhia fornecedora de energia elétrica e seria possível escolher uma entre quatro fontes para a transformação de energia, onde a escolhida seria aquela que melhor correspondesse à realidade da cidade.

Pode-se notar que além das questões tecnológicas envolvidas, e da transposição do conteúdo, os estudantes dessa equipe também se atentaram ao papel na sociedade que essa exposição poderia ter e isso corresponde a um dos objetivos dos museus de ciências (MARANDINO, 2008); essa característica pode ser verificada, quando se depara com aspectos ambientais e sociais abordados pelo jogo. Essas características além de irem ao encontro da proposta do museu, também se configuram de um saber social despertado e agregado pelos estudantes (TARDIF, 2002).

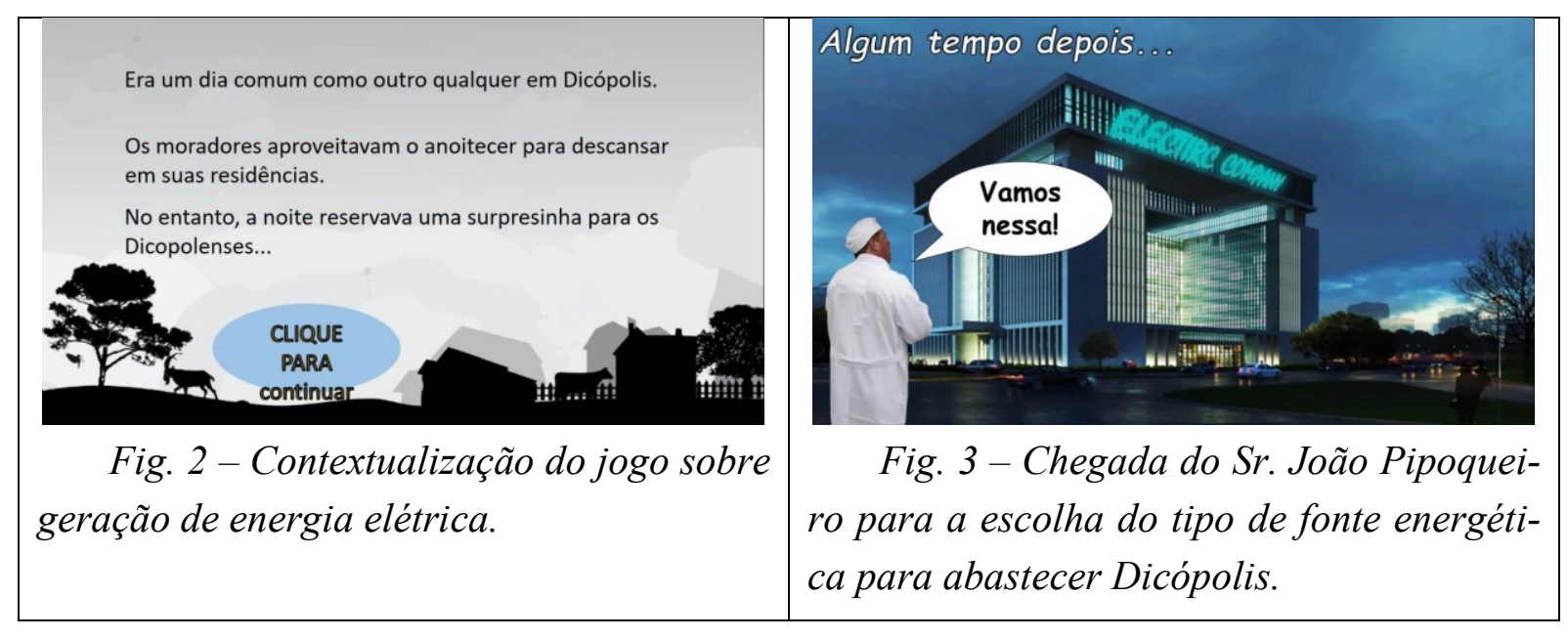




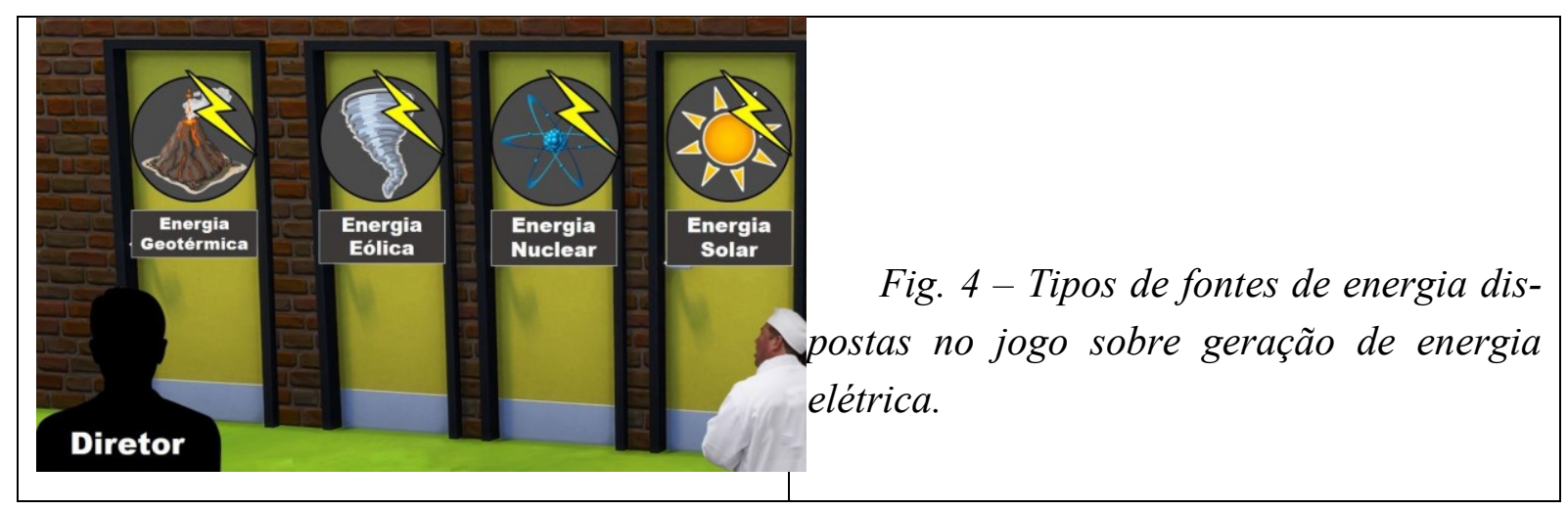

\section{VIII.3 Grupo 3: Desafio e Superação}

O grupo 3 passou por um desafio maior, pois precisava ainda compreender os objetivos da atividade proposta pelo professor e fazer uma proposta adequada. Assim, esse grupo teve um trabalho bastante intenso durante essa etapa.

Assim, nas semanas seguintes à apresentação da Etapa 2, o grupo procurou a equipe do Museu DICA e buscou conhecer melhor os objetivos da exposição. Os diálogos com a equipe e a compreensão do espaço do museu e dos recursos disponíveis levou a equipe a abraçar a ideia do DICA para dialogar com o público por meio do código QR. Assim, o grupo e decidiu construir conteúdos, utilizando o código $\mathrm{QR}$, para colaborar com a interação do público com a exposição "Eletromagnetismo: História e Cotidiano".

No entanto, em conversas com os colaboradores da disciplina, os estudantes desse grupo evidenciaram que não se sentiam satisfeitos com sua proposta, por acreditarem que se tratava de um trabalho menor e não conseguiam enxergar como um conteúdo apresentado dessa forma poderia contribuir para a exposição. Nesse momento, percebemos que as confusões e dificuldades apresentadas nas etapas anteriores por essa equipe, eram um reflexo de sua insegurança em relação ao produto que estavam tentando oferecer. Assim, por não compreenderem o papel da comunicação e as diversas relações que o museu pode estabelecer com seus visitantes, a equipe não se sentiu confortável ou capaz de propor uma atividade.

Como colaboradores da disciplina, representantes do setor educativo do Museu DICA e responsáveis pelo desenvolvimento dessa pesquisa, procuramos, juntamente com o professor da disciplina, dialogar com esses alunos para tentar colaborar para que eles pudessem fazer uma proposta da qual se orgulhassem, esclarecendo questões acerca do papel da comunicação e as relações com o público, indicando que refizessem a leitura do texto de Marandino (2008), para ajudar em suas reflexões.

Desse modo, no dia da apresentação final, o grupo trouxe uma proposta de organização dos conteúdos que foi especialmente valorizada pelo uso do código $\mathrm{QR}$, mostrando um amadurecimento em relação às suas ideias acerca da transposição museográfica e os objetivos educativos do museu.

Assim, os conteúdos propostos pela equipe traziam explicações sobre os objetos da exposição e os conceitos físicos envolvidos em cada um, organizados em dois níveis diferen- 
tes de complexidade e disposta em páginas separadas (para serem disponibilizadas no site do Museu DICA) e que poderiam ser acessados pelos visitantes, por meio do código QR, de acordo com o interesse de cada visitante. O primeiro nível de complexidade apresentava os conceitos envolvidos na interação com determinado objeto de maneira bastante simplificada e superficial. Os visitantes que desejassem uma explicação mais aprofundada (com um texto maior e mais elaborado) deveriam buscar o segundo nível de complexidade disponível.

Para o desenvolvimento do trabalho a equipe escolheu quatro objetos da exposição que mais evidenciavam o tema de interações eletromagnéticas: a bonina de tesla, o painel solar fotovoltaico, o eletróforo de Volta e uma bobina de indução magnética.

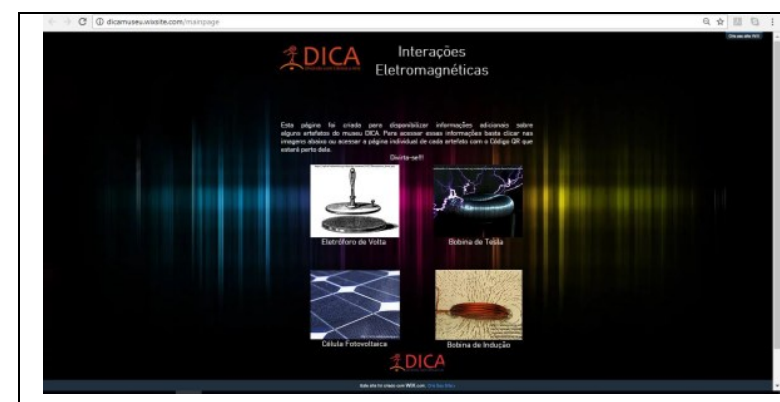

Fig. 5 - Página inicial dos experimentos escolhidos para contextualizar interações eletromagnéticas.

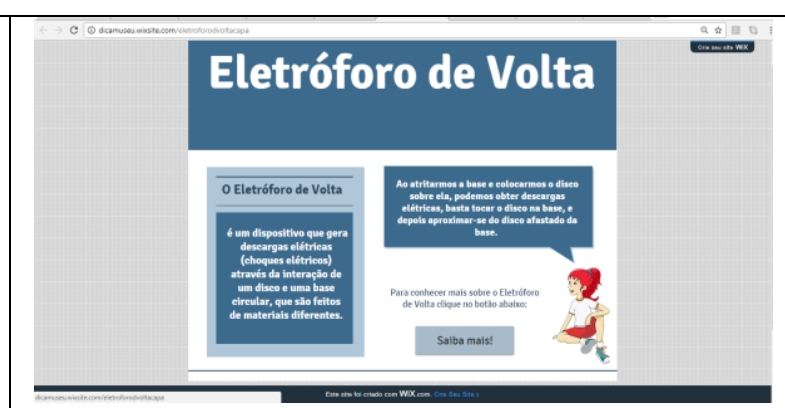

Fig. 6-Primeiro nível de informações sobre o Eletróforo de Volta.

Na Fig. 6, pode-se notar um pouco da estrutura adotada, onde as fontes e cores foram utilizadas de melhor forma que na página inicial. Além disso, pode-se notar também, a clareza na exposição do conteúdo, além da disposição de uma parte falando o que é o experimento e outra com os conceitos físicos envolvidos. Ao final há um botão caso visitante queira saber um pouco mais sobre os objetos.

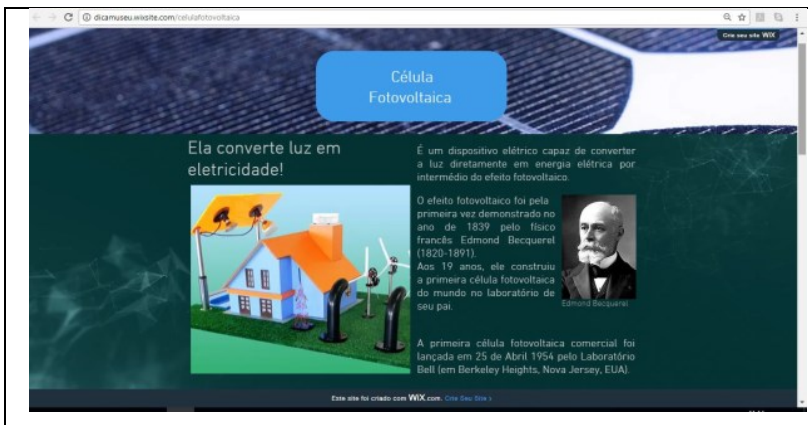

Fig. 7 - Primeira parte no segundo nível de informações sobre placas fotovoltaicas.

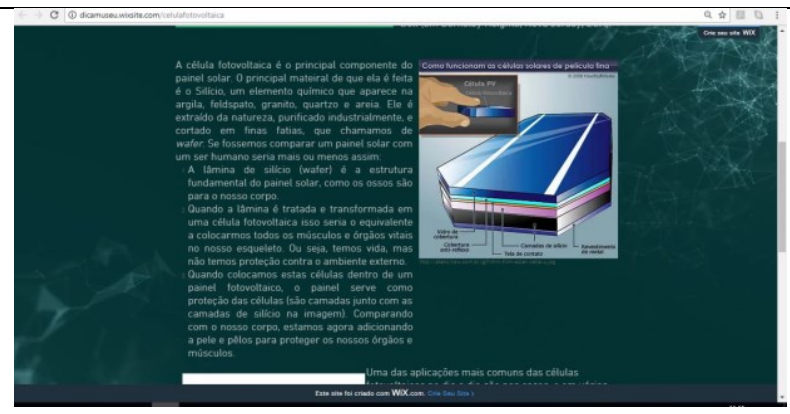

Fig.8 - Segunda parte no segundo nível de informações sobre placas fotovoltaicas.

Uma segunda parte, após clicar para saber mais sobre o objeto, abre-se uma página com informações mais técnicas, por exemplo: montagem do sistema que constitui o equipamento em questão, um discorrimento mais detalhado sobre a física envolvendo o experimen- 
to, assim como aplicações desse material no cotidiano. Também é notado um pouco de história de ciência, onde é abordado o contexto da época e qual o pessoal envolvido quando houve a construção desse tipo de conhecimento.

Os elementos acima destacados sobre o artefato, ressalva características importantes da transposição museográfica (ALLARD et al., 1996; CHEVALLARD, 1991; MARANDINO, 2001-b; DESVALLÉES; MAIRESSE; 2013) onde é possível notar as características que esse tipo de conteúdo contém em relação como e para quem estará disposto. Além disso, notase a evolução nos conhecimentos adquiridos, sobre transposição museográfica e educação em museus, e agregados aos componentes dessa equipe, criando um início propício para a construção de um saber experiencial em relação à educação em museus (TARDIF, 2002). Além disso, os QRCodes foram criados de fato.

\section{VIII.4 Reflexões sobre as propostas finais}

Assim, apesar das dificuldades percebidas durante a construção dos artefatos (em relação ao entendimento quanto ao referencial sobre educação em museus e a proposta de artefato digital que deveriam elaborar, considerando o contexto do Museu DICA) notou-se uma evolução na compreensão dos estudantes de PIPE 3, tanto em relação à visão do museu de ciência (o qual deve ser considerado como um espaço diferente da escola, porém, também com objetivos educacionais, onde deve-se respeitar sua pedagogia própria); como na transposição dos conteúdos, os quais devem estar acessíveis a todos os públicos.

Desse modo, os 3 grupos cumpriram com os objetivos da atividade proposta pelo professor e tiveram a oportunidade de colaborar com uma exposição para o museu de ciência. A Tabela 3 nos mostra um panorama desse aprendizado, evidenciando que todos os grupos foram capazes de fazer propostas adequadas aos objetivos iniciais da disciplina e compreenderam alguns elementos importantes para a pedagogia do museu.

Tabela 3 - Propostas Finais dos estudantes e suas relações com o museu e as tecnologias: (N) - não entenderam; (S) - entenderam; (T) evidências superficiais.

\begin{tabular}{|l|l|l|l|}
\hline & \multicolumn{1}{|c|}{ Grupo 1 } & \multicolumn{1}{c|}{ Grupo 2 } & \multicolumn{1}{c|}{ Grupo 3 } \\
\hline Proposta Final & $\begin{array}{l}\text { Quiz interativo, sobre ele- } \\
\text { trostática no cotidiano, com } \\
\text { um discurso que busca apro- } \\
\text { ximar os visitantes do artefa- } \\
\text { to. }\end{array}$ & $\begin{array}{l}\text { Jogo interativo em que um } \\
\text { personagem é responsável } \\
\text { por ajudar o visitante a } \\
\text { entender e refletir sobre as } \\
\text { diferentes formas de gera- } \\
\text { ção de energia. }\end{array}$ & $\begin{array}{l}\text { Apresentação de con- } \\
\text { ceitos e conteúdos } \\
\text { relativos aos objetos da } \\
\text { exposição, em dois } \\
\text { níveis de complexida- } \\
\text { de, por meio de código } \\
\text { QR. }\end{array}$ \\
\hline $\begin{array}{l}\text { Entendimento sobre a } \\
\text { museografia da exposição }\end{array}$ & $\mathrm{S}$ & $\mathrm{S}$ & $\mathrm{S}$ \\
\hline Reconhecimento do Museu & $\mathrm{S}$ & $\mathrm{S}$ & \multicolumn{1}{c|}{$\mathrm{S}$} \\
\hline
\end{tabular}




\begin{tabular}{|l|c|c|c|}
\hline como espaço educativo & $\mathrm{S}$ & $\mathrm{S}$ & $\mathrm{S}$ \\
\hline $\begin{array}{l}\text { Linguagem apropriada e } \\
\text { qualidade da transposição }\end{array}$ & $\mathrm{S}$ & $\mathrm{S}$ & $\mathrm{S}$ \\
\hline $\begin{array}{l}\text { Uso de tecnologias (ade- } \\
\text { quação aos objetivos da } \\
\text { disciplina) }\end{array}$ & & & \\
\hline
\end{tabular}

Os resultados apresentados nos levam a acreditar que o processo de compreensão dos objetivos dos museus de ciências não é trivial, assim, acreditamos que as ações desenvolvidas nesse trabalho podem contribuir para que esses alunos, futuros professores de Física, possam se apropriar do espaço do museu em sua atuação docente, reconhecendo-o enquanto espaço educativo e de apropriação para suas práticas (TARDIF, 2002) e, assim, colaborar para uma relação mais próxima entre o museu e a escola, por compreender melhor as diferenças e semelhanças desses espaços em relação aos seus objetivos educacionais (MARANDINO, 2008).

\section{Considerações finais}

Este trabalho buscou compreender o processo de formação inicial de professores de Física, da UFU, por meio da construção de artefatos museais digitais. Então, no início da trajetória (para a confecção dos trabalhos) ficou evidente que algumas lacunas foram deixadas em segundo plano ao discutir-se o referencial sobre educação em museus com os estudantes, principalmente sobre as questões museográficas, porém puderam ser solucionadas devido à identificação delas ao longo do processo de construção do conhecimento no desenvolvimento dos artefatos.

A partir disso, pode-se afirmar que houve a agregação de um saber profissional (TARDIF, 2002) relacionado à educação em museus, diante das habilidades desenvolvidas e apresentadas pelos estudantes em todo o curso. Dessa forma, criando condições propícias para o desenvolvimento do saber experiencial com relação à educação em museus, pois, durante essa etapa da formação profissional houve uma condição inicial de inserção na profissão, um choque com a realidade dos museus diante de seus públicos e propostas da educação museal, além de uma oportunidade de aprendizagem na prática e descoberta de seus limites diante da experiência que possuem e ainda podem adquirir.

Nesse sentido, também se identificou que houve um preparo dos estudantes em formação inicial quanto à contextualização das TDIC (MARANDINO, 2001; MINTZ 2005), julgando que, enquanto educadores, devem estar preparados para uma abordagem cada vez mais tecnológica.

Desse modo, constatamos as ideias de Ovigli (2009) e Silva (2012) quanto à inserção de atividades extraescolares e/ou em espaços não formais durante a formação inicial, ou seja, que esse tipo de iniciativa pode despertar habilidades nos estudantes quanto ao estudo e co- 
nhecimento do conteúdo a ser trabalhado. Logo, notamos aspectos - a partir do tratamento realizado com os conceitos - que os garantem serem compreensíveis a todos os públicos.

Ainda sobre o processo desenvolvido nessa disciplina, Queiroz e De Castro Catarino (2012) citam sobre a formação inicial de professores e o que um profissional desse tipo deve absorver durante a sua constituição enquanto docente, que na perspectiva desta pesquisa, isso corrobora com as ideias de Ovigli (2009) e Silva (2012) sobre a formação de professores e a atuação destes em espaços diferentes da escola, em especial nos museus de ciências. Logo, os estudantes de PIPE 3 mostraram de forma vitoriosa ter conquistado tais características.

\section{Agradecimentos}

Aos estudantes de PIPE 3 pelo empenho e os ótimos trabalhos desenvolvidos e a grande contribuição com a exposição de Eletromagnetismo; ao CNPQ pelos recursos financeiros que subsidiaram a pesquisa; ao NUTEC, pela colaboração com a parte de recursos tecnológicos; ao Museu DICA pela aceitação do artefato como parte da exposição; à Flávia Machado pela contribuição na orientação e apresentação das propostas; ao professor da disciplina Eduardo Kojy Takahashi pela aceitação da proposta de trabalho.

\section{Referências}

ACHIAM, M. Didactic Transposition: The transformation and translocation of science in museums. 2014.

ALLARD, M. et al. La visite au musée, in Réseau. Canadá, p. 14-19, Décembre 1995/Jan 1996.

ARAÚJO, R. S.; VIANNA, D. M. A formação de professores de Física no Brasil sob uma perspectiva histórica. In: SIMPOSIO DE INVESTIGACIÓNEN EDUCACIÓNEN FÍSICA, 9, 2008, Rosário. Anais... Rosário: APFA. 2008. Disponível em:

$<$ https://www.researchgate.net/profile/Deise_Vianna/publication/228422990_A_formacao_de professores_de_Fisica_no_Brasil_sob_uma_perspectiva_historica/links/5452bbff0cf2cf5164 7a4960.pdf>. Acesso em: 02 nov. 2019.

BARROS, M.; MARTINS, S. O museu DICA e a escola: a percepção dos professores. In: SIMPÓSIO NACIONAL DE ENSINO DE FÍSICA, 21, 2015, Uberlândia. Atas... São Paulo: Sociedade Brasileira de Física, 2016. Disponível em:

$<$ http://www.sbfl.sbfisica.org.br/eventos/snef/xxi/sys/resumos/T1033-2.pdf $>$. Acesso em: 02 nov. 2019. 
BRUNO, C. A indissolubilidade da pesquisa, ensino e extensão nos museus universitários. Cadernos de Sociomuseologia, [S.1.], v. 10, n. 10, june 2009. Disponível em: $<$ https://revistas.ulusofona.pt/index.php/cadernosociomuseologia/article/view/301>. Acesso em: 04 nov. 2019.

CARVALHO, M. A. Um estudo sobre a inserção de atividades em educação não formal na disciplina Metodologia e Prática do Ensino de Física da Universidade Estadual de Londrina. 2009. 136 p. Dissertação (Mestrado em Ensino de Ciências e Educação Matemática) - Programa de Pós-Graduação em Ensino de Ciências e Educação Matemática, Universidade Estadual de Londrina.

CHEVALLARD, Y. La Transposición Didáctica: del saber sabio al saber enseñado. Editora Aique, Argentina, 1991.

COLOMBO JUNIOR, P. D. Inovações Curriculares em Ensino de Física Moderna: Investigando uma Parceria entre Professores e m Centro de Ciências. 2014. 305 p. Tese (Doutorado) - Programa de Pós-Graduação Interunidades em Ensino de Ciências, Faculdade de Educação, Universidade de São Paulo, São Paulo.

DESVALlÉES, A.; MAIRESSE, F. Conceitos-chave de Museologia. Tradução: Bruno Brulon Soares; Marília Xavier Cury. São Paulo: ICOM, 2013.

JACOBUCCI, D. F. C. Contribuições dos espaços não-formais de educação para a formação da Cultura Científica. Em Extensão, Uberlândia, v. 7, 2008.

LÜDKE, M.; ANDRÉ, M. Pesquisa em Educação: abordagens qualitativas. São Paulo: Editora Pedagógica e Universitária, 1986.

MCMANUS, P. Memories as indicators of the impact of museum visits. International Journal of Museum Management and Curatorship, n. 12, p. 367-380, 1993.

MARANDINO, M. INTERFACES NA RELAÇÃO MUSEU-ESCOLA. Caderno Catarinense de Ensino de Física. São Paulo, v. 18, n. 1, p. 85-100, abr. 2001.

MARANDINO, M. O Conhecimento Biológico nas Exposições de Museus de Ciências: análise do processo de construção do discurso expositivo. 2001-b. 434 f. Tese (Doutorado) - Curso de Programa de Pós-graduação em Educação, Faculdade de Educação da Universidade de São Paulo, Universidade de São Paulo, São Paulo. 
MARANDINO, M. Educação, comunicação e museus. In: MARANDINO, M. Educação em Museus: mediação em foco. São Paulo: Geenf/ FEUSP, 2008. Cap. 1. p. 7-17.

MARANDINO, M. The expositive discourse as pedagogical discourse: studying recontextualization in the production of a science museum exhibition. Cultural Studies of Science Education, v. 11, n. 2, p. 481-514, 2016.

MINTZ, A. Science Society and Science Centers. História, Ciências, Saúde: Manguinhos, V.12 (suplemento), p. 267-280, Rio de Janeiro, 2005.

OLIVEIRA, R. I. R. Utilização de Espaços Não Formais de educação como estratégia para a promoção de aprendizagens significativas sobre evolução biológica. 2011. 155p. Dissertação (Mestrado em Ensino de Ciências) - Faculdade UnB Planaltina, Universidade de Brasília.

OVIGLI, D. F. B. Os saberes da mediação humana em centros de ciências: contribuições para a formação inicial de professores. 2009. 228 p. Dissertação (Mestrado) - Universidade Federal de São Carlos, São Carlos.

OVIGLI, D. F. B.; BERTUCCI, M. C. S. A formação para o ensino de ciências naturais nos currículos de pedagogia das instituições públicas de ensino superior paulistas. Ciências \& Cognição, v. 14, n. 2, p. 194-209, 2009.

QUEIROZ, G. P. C.; DE CASTRO CATARINO, G. F. A formação inicial de professores de Física a partir da prática de projetos. Revista de Educação, Ciências e Matemática, v. 2, n. $2,2014$.

ROBILOTTA, M. R.; BABICHAK, C. C. Definições e conceitos em Física. Cadernos Cedes, v. 41, p. 35-45, 1997.

SANTOS, N. F. A formação inicial de professores de Física em Centros Federais De Educação Tecnológica: contribuições e críticas. 2004. 140 p. Dissertação (Mestrado em Educação) - Centro de Educação e Humanidades, UERJ.

SILVA, L. de F. Um estudo da monitoria de licenciandos em um centro de ciências para a melhoria da formação inicial de professores de física. 2012. 85p. Dissertação (Mestrado em Ensino de Ciências) - Programa de Pós-Graduação em Educação para a Ciência, Faculdade de Ciências, UNESP, Campus Bauru. 
TARDIF, Maurice et al. Saberes docentes e formação de professores. São Paulo: Vozes, 2002.

UFU. Instituto de Física. Projeto pedagógico do curso de graduação em Física - Licenciatura Plena, 2007. Disponível em:

$<$ http://www.infis.ufu.br/images/arquivos/licenciatura/FI_ProjetoPedagogico.pdf $>$. Acesso em: 1 nov. 2019. 